\title{
GCU
}

Glasgow Caledonian

University

University for the Common Good

\section{Manage reverse power flow and fault current level in Iv network with high penetration of small scale solar and wind power generation}

Bangash, K N; Farrag, M E A; Osman, A H

Published in:

2018 53rd International Universities Power Engineering Conference (UPEC)

DOI:

10.1109/UPEC.2018.8541923

Publication date:

2018

Document Version

Author accepted manuscript

Link to publication in ResearchOnline

Citation for published version (Harvard):

Bangash, KN, Farrag, MEA \& Osman, AH 2018, Manage reverse power flow and fault current level in Iv network with high penetration of small scale solar and wind power generation. in 2018 53rd International Universities Power Engineering Conference (UPEC)., 8541923, IEEE, 2018 53rd International Universities Power Engineering Conference (UPEC), Glasgow, United Kingdom, 4/09/18.

https://doi.org/10.1109/UPEC.2018.8541923

\section{General rights}

Copyright and moral rights for the publications made accessible in the public portal are retained by the authors and/or other copyright owners and it is a condition of accessing publications that users recognise and abide by the legal requirements associated with these rights.

Take down policy

If you believe that this document breaches copyright please view our takedown policy at https://edshare.gcu.ac.uk/id/eprint/5179 for details

of how to contact us. 


\section{Manage Reverse Power Flow and Fault Current Level in LV Network with High Penetration of Small Scale Solar and Wind Power Generation}

\author{
K.N. Bangash \\ Electrical department, College of \\ Engineering \\ American University of Sharjah \\ Sharjah, UAE \\ kbangash@aus.edu
}

\author{
M.E.A. Farrag \\ School of Engineering and Built \\ Environment \\ Glasgow Caledonian University \\ Glasgow, UK \\ Faculty of Industrial Education, \\ Helwan University, Egypt \\ Mohamed.Farrag@gcu.ac.uk
}

\author{
A.H. Osman \\ Electrical department, College of \\ Engineering \\ American University of Sharjah \\ Sharjah, UAE \\ aosmanahmed@aus.edu
}

\begin{abstract}
High penetration level of rooftop small-scale renewable energy generation (REG) such as solar and wind power into the existing low voltage $(\mathrm{LV})$ network would cause the flow of power in reverse direction. This would also vary the level of short-circuit current required for relays to operate. Relay settings would be required to properly detect the unpredictable fault current and isolate the faulty section. This paper investigates the impact of residential distributed generation (DG) penetration level on the typical UK low voltage network protection system. Studies were commenced to properly charge and discharge the home connected energy storage battery (ESB). ESB is used as a remedial measure to confine the flow of reverse power due to rooftop DGs. Penetration level DGs are modeled based on proper ESB charging and discharging states in daily load cycle. Short circuit analysis is simulated on Matlab/Simulink. The power flow from the transformer secondary is managed to avoid malfunctioning of relays according to daily load cycle. Short circuit analysis results are compared with the UK passive network to investigate the impact of the DG on the short circuit currents at distribution transformer.
\end{abstract}

Keywords - Rooftop DG penetration, UK distribution network, energy storage batteries, short circuit analysis, reverse power flow

\section{INTRODUCTION}

Small rooftop solar and wind power generation of homeowner and communities projects would be the key opportunities for the planner to meet future electricity demand. The existing electrical grid infrastructure was originally designed to supply power from the source to load. But with an extensive increase of power production from DGs as a result of very low tariff for home power producer, reverse power may flow from LV to MV network that imposes technical challenges [1]. DG causes the system to lose its radial power flow and increase the fault level of the system so protection relay settings should be changed. High penetration of DGs might cause overvoltage at the point of connection, particularly at LV network. Some types of DGs are connected to the grid via power converters that inject harmonics into the system and quality of power is affected. Some of renewable DGs are intermittent in nature that results in fluctuation in the production of power. Technical measures are required to eliminate those negative impacts while still enabling the full benefits of renewable energy [2]. Power generation capacity and network reliability would be improved with DGs but intermittent nature of renewable power generation can affect system stability. Utility companies would curtail energy production particularly during high power production but low demand, particularly during daytime [3].

It is expected that the DGs may be operated in islanding mode but the electrical energy generated from PV panels or wind turbines is in unfavorable conditions as intermittent in nature [4]-[5]. The intermittent behavior of solar and wind energy has made it imperative to analyze the daily load cycle and use energy storage battery to store energy along with system reliability. Energy storage is required at LV distribution network to store excessive electric energy generated by DGs and supply power back during low generation times and high demand.

This research work analyses the high penetration level of rooftop solar and wind power DGs and its impacts on fault current contribution of UK LV network. Results of short circuit analysis are compared with the UK passive network. Energy storage batteries in presence of DGs are used to confine the reverse flow of power at distribution transformers. DGs with batteries would allow a suitable amount of fault current to flow from the transformer side, which would avoid mal-trip and fail to trip of relays. UK LV network is simulated in Matlab/Simulink software. The rest of the paper is organized as follows. Section II explains the fundamentals of system protection with a high penetration level of DG. Section III presents the modeling of UK rooftop DG penetration level at LV network. Section IV illustrates the simulation results of fault analysis with DG, EVs, and energy storage batteries. Section V concludes the paper.

\section{SYSTEM FUNDAMENTALS}

In conventional distribution network, fault current travel from the grid in the downstream direction. The overcurrent relays are uni-directional in nature. In the future active distribution system, penetration level and location of DG can 
change the network configuration. Fig. 1 shows the part of the distribution network. The penetration level of DG1 and DG2 would reduce the fault current share from the grid. The protection systems can fail by not removing the faulty component (fail to trip) CB2 if DG2 penetration level is higher as the fault current will be shared by DG2. In case, DG1 penetration level is much higher most fault current will be shared by DG1 that can trip the breaker CB3 known as mal to trip. Moreover, the presence of DG1 and DG2 may cause protection deficiency called "reduction of reach". Fault current seen by the relay at CB1 would be reduced which can lead to improper operation of overcurrent relays [6]-[7]-[8].

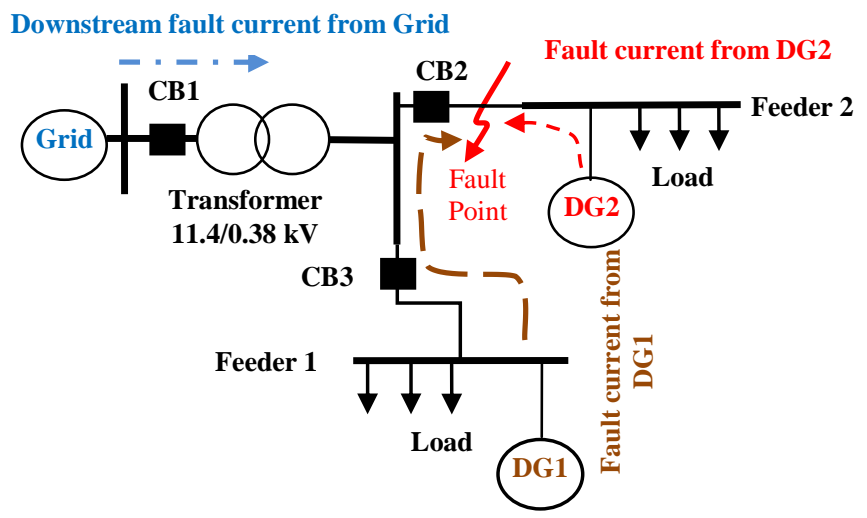

Fig. 1. Flow of fault current in distribution feeder with DGs

\section{MODELING OF DG PENETRATION LEVEL}

Typical UK distribution network model discussed in [9][10] is used in this paper with DGs, mainly from rooftop Photovoltaic (PV) generations and wind power. Summer home load profile at a bright sunny day of UK is selected as shown in Fig. 2. Because rooftop PV $(3 \mathrm{~kW})$ generation during daytime is more than home load consumption so reverse power flow is observed. The wind power generation data pattern is collected from the rooftop wind generator $(6 \mathrm{~kW})$ at Glasgow Caledonian University campus.

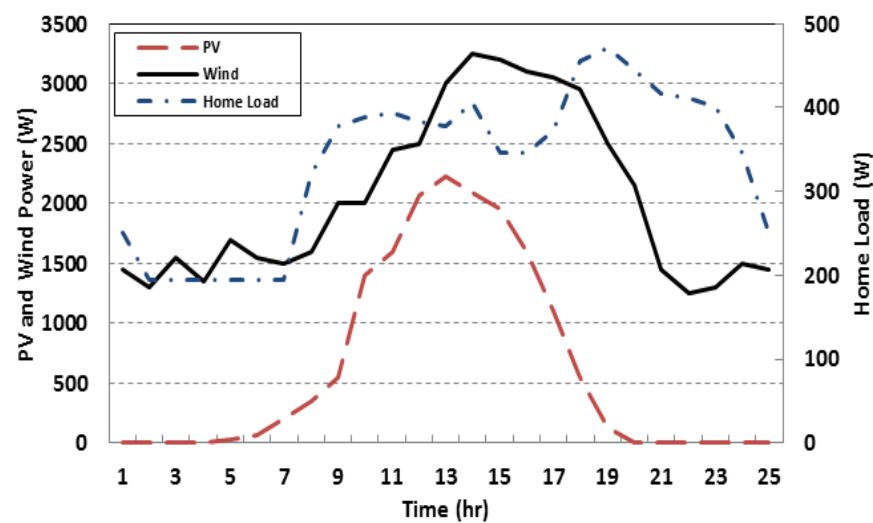

Fig. 2. Home load profile, PV and wind production for 24 hour period (Summer season)

In this research, $11 / 0.4 \quad \mathrm{kV} \quad 500 \mathrm{kVA}$ distribution transformer is selected as a reference to model the percentage penetration level of DG at LV network. Fault current level is analyzed based on DG penetration levels. Individual penetration level percentage of wind turbines, PVs generation and total DG percentage level with respect to $500 \mathrm{kVA}$ transformer are analyzed as shown in Fig. 3.

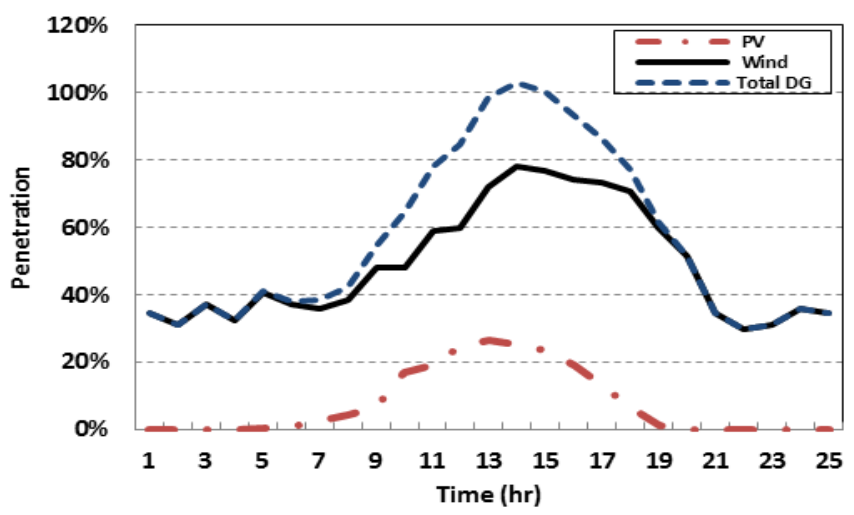

Fig. 3. \% DG penetration level (78\% wind, $25 \%$ PV) and $\%$ home load

Percentage DG penetration level at both ends of the day is more than $30 \%$. At mid-day, it has touched $100 \%$ of the transformer capacity as shown in Fig. 3. With high penetration level of DG reverse power flow has increased and reached a maximum level in the middle of the day as shown in Fig. 4.

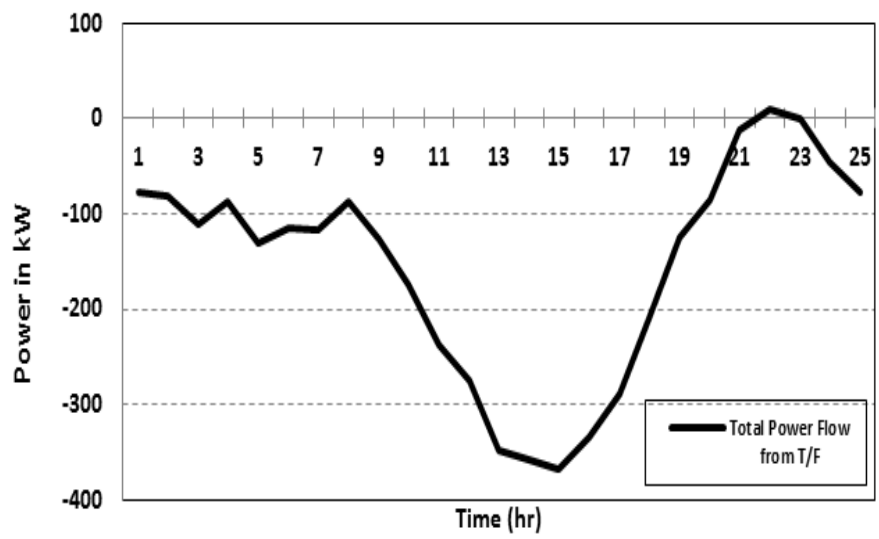

Fig. 4. Total power flow from $500 \mathrm{kVA}$ transformer for $103 \%$ DGs penetration

\section{A. Impact of EVs and Energy storage batteries on reverse power flow}

EVs can be initiated as real power load demand on LV distribution network during high renewable DG power production. Out of 384 homes, 220-240 EVs are charged throughout the day. Standard $3 \mathrm{~kW}$ domestic chargers are used for 6 hours in this research work [11]-[12]-[13]. The slot of 60 EVs are charged one after the other for 6 hours bringing 180 kW extra load during $24 \mathrm{hrs}$ load cycle as shown in the Fig. 5. EVs are not charged in morning time while driving to offices and evening peak hours. This extra load is about $39 \%$ of the transformer. 


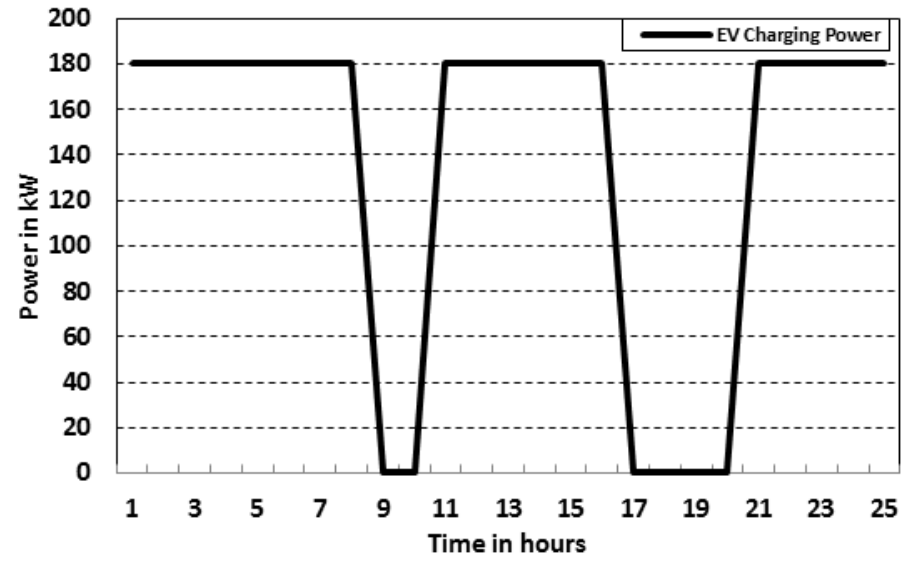

Fig. 5. Load profile of $60 \mathrm{EVs}$

In this research total of 200 home batteries with a rating of $1 \mathrm{~kW}$ is used. Numbers of batteries may be varied depending upon manufacturer capacities. Small size Lithium-ion batteries ranging from $1-10 \mathrm{kWh}$ are available to maximize the PV consumption by storing electricity during off-peak times [14]. During peak production of power from DGs, batteries at homes are charged. In daily load cycle, batteries are required to charge in mid-day and discharged during both ends of the day i.e. from 0 to $8 \mathrm{hrs}$ and 20 to $24 \mathrm{hrs}$. Fig. 6 shows power produced and consumed by the batteries during charging and discharging cycle in $24 \mathrm{hrs}$.

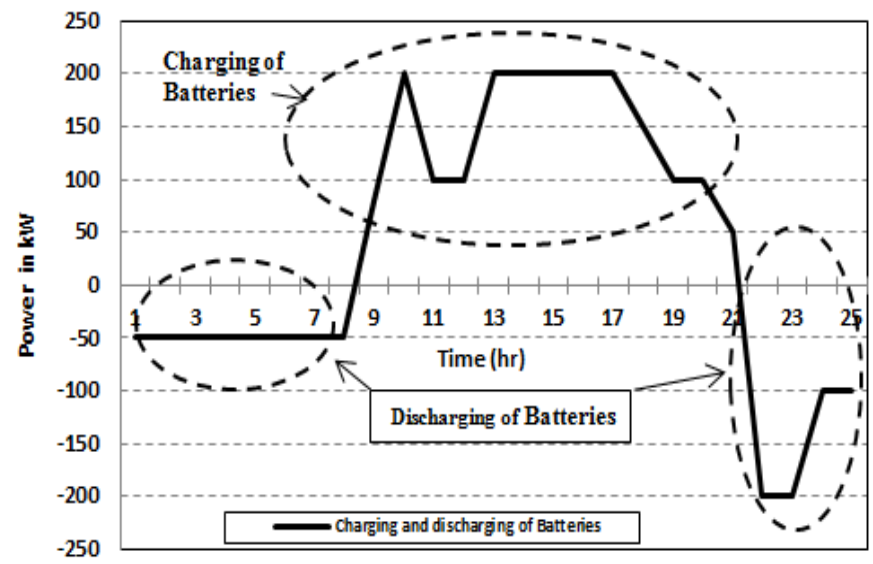

Fig. 6. Power consumed and produced by the batteries during charging and discharging

Fig. 7 shows flow of power from $500 \mathrm{kVA}$ transformer when batteries are charged and discharged. It is obvious that high production of power is required in mid-day to charge the batteries and less power generation at both ends of the day to discharge batteries. To achieve this wind penetration level is decreased and PV generation is increased. Otherwise, with a high penetration level of wind, there will be not a sufficient time for batteries to discharge at both ends of the day. This will also allow power to flow downstream for protection. Otherwise, without batteries, it would be impossible for homes to generate power.

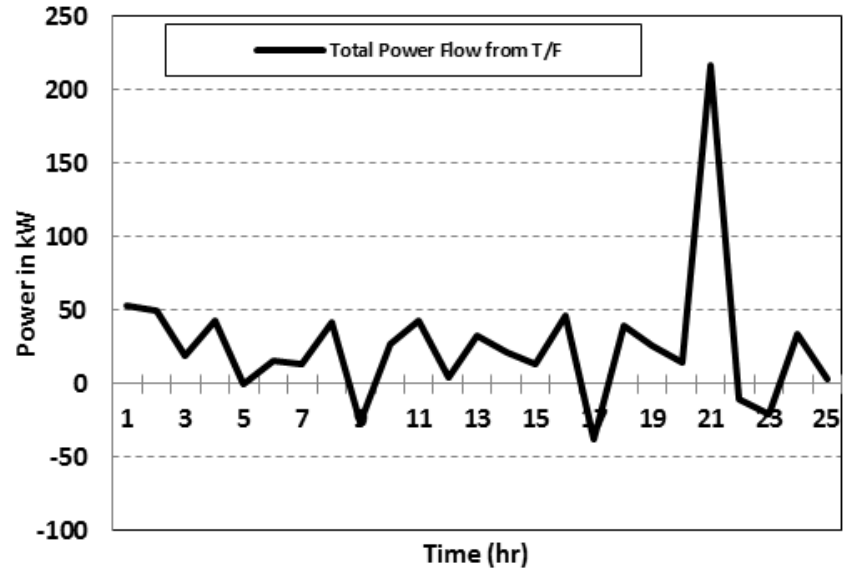

Fig. 7. Total power flow from $500 \mathrm{kVA}$ transformer with $78 \%$ wind, $25 \% \mathrm{PV}, 39 \% \mathrm{EVs}$ and $40 \%$ batteries

The penetration level of wind is reduced to $26 \%$ and penetration level of PV is increased to $53 \%$. With this scheme, batteries would be able to discharge at both ends of the day and charged at mid-day when PV power production is at maximum. Fig. 8 shows the power flow from the transformer. By proper penetration of DGs, EVs and energy storage batteries reverse power flow can be averted. High reverse power is not required as it will be required to change the protection schemes, relay settings as well as voltage rise.

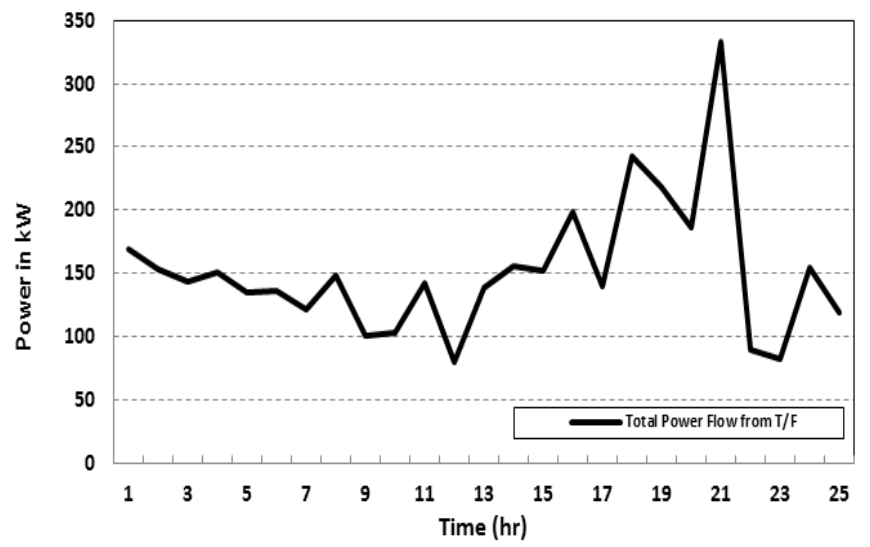

Fig. 8. Total power flow from $500 \mathrm{kVA}$ transformer with $26 \%$ wind, $53 \%$ $\mathrm{PV}, 39 \% \mathrm{EVs}$ and $40 \%$ batteries

\section{SIMULATION RESULTS}

In UK distribution network, high rupturing capacity (HRC) fuses are used for the protection of LV circuits. The LV fuse rating of a $500 \mathrm{kVA}$ transformer as per British standard BS88 part 5 is shown in Table I [15].

TABLE I. LV FUSE RATING

\begin{tabular}{|c|c|c|c|}
\hline $\begin{array}{c}\text { Transformer } \\
\text { Size } \\
\text { (kVA) }\end{array}$ & $\begin{array}{c}\text { Max } \\
\text { Fuse } \\
\text { size }\end{array}$ & $\begin{array}{c}\text { Normal fuse size } \\
\text { non- electric } \\
\text { heating }\end{array}$ & $\begin{array}{c}\text { Residential } \\
\text { electric heating \& } \\
\text { Industrial } / \\
\text { Commercial }\end{array}$ \\
\hline 500 & $400 \mathrm{~A}$ & $315 \mathrm{~A}$ & $400 \mathrm{~A}$ \\
\hline
\end{tabular}




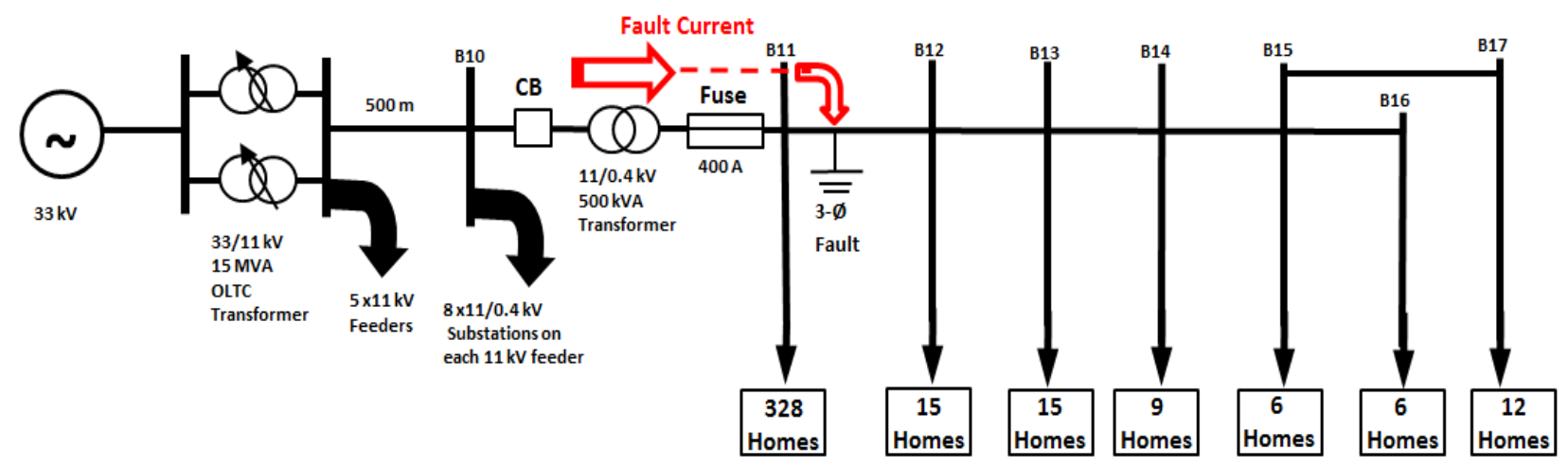

Fig. 9. Flow of current during fault at UK radial network

The schematic diagram of the simulated UK distribution network is shown in Fig. 9. The only single $11 / 0.4 \mathrm{kV}$ feeder is selected for simulation study in this research paper. 11/0.4 kV substation supplies 384 properties distributed along outgoing radial feeders. At each case three-phase fault is applied between node B11 and B12 and short circuit analysis is conducted. Three phase fault is removed after 0.1 seconds so inverter base DG remains connected during fault time as per G83/2 and G59/1 Engineering Recommendations. In this research work fault contributed from upstream $11 \mathrm{kV}$ side of $500 \mathrm{kVA}$ distribution transformer is analyzed. The current in both directions at the LV side of the transformer (bus B11) is measured.

Short circuit analysis is conducted on UK passive network that illustrates the reference fault level during a short circuit. The fault level with high penetration of DGs is compared with reference fault level. Finally, EVs and energy storage batteries are used as remedial measures to confine the flow of short circuit current contributed by DG at $400 \mathrm{~V}$ network.

\section{A. Fault Analysis of Domestic Load without DG}

Typical daily load profile over 24 hours was simulated on UK distribution network. The hourly load is scaled down in seconds so that fault analysis may be conducted. Phase current profile at the secondary side of the transformer is shown in the Fig. 10.

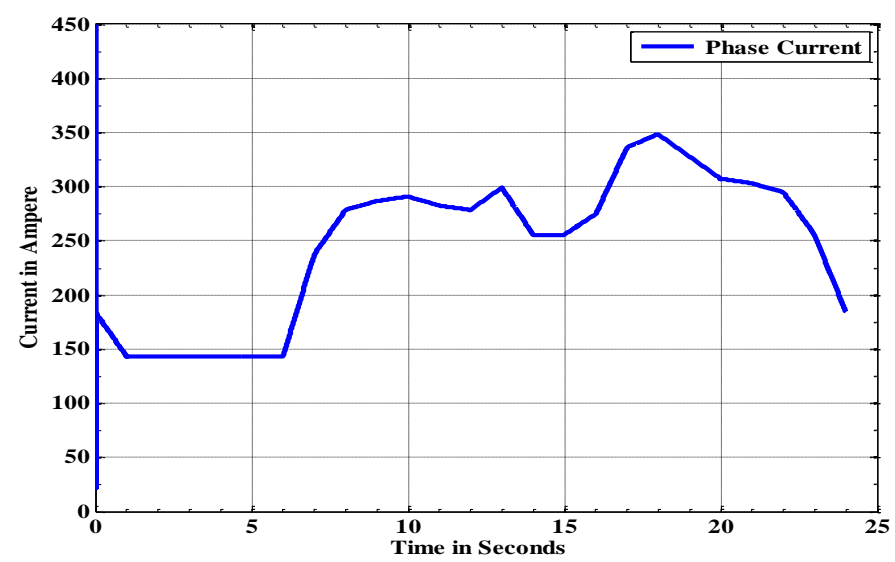

Fig. 10. Phase current profile at LV side of TF
Three phase short circuit fault is applied at $5 \mathrm{sec}$ and removed at $5.1 \mathrm{sec}$. This is the time when minimum current is flowing towards residential properties and the share of fault current from the substation can be analyzed. Fault current of 450 Ampere is contributed by the substation as shown in Fig. 11. This amount of current is well enough to pick up the signal and circuit breaker would trip before the fuse is blown up.

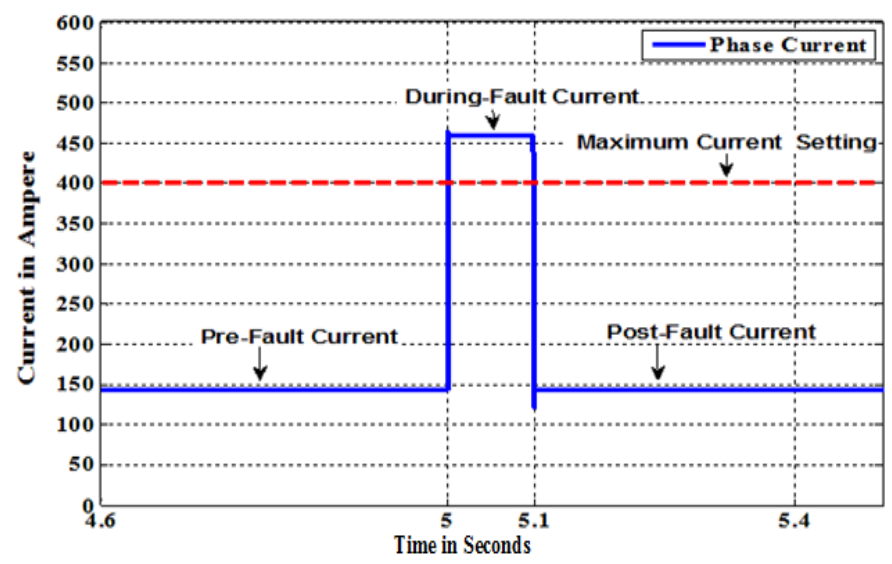

Fig. 11. Fault current contributed by the substation

\section{B. Short circuit Analysis with $78 \%$ Wind and $26 \%$ PV}

The high penetration level of DG injects power into the grid. High reverse power flow towards upstream $11 \mathrm{kV}$ network may exceed the pickup current of the relays. This would result in the tripping of $\mathrm{CB}$ initiated by overcurrent relay although not a fault current. Hence, at a high penetration level of DG rating of fuses and settings of $\mathrm{CB}$ may be required to update. Moreover, bi-directional current relays would be required to anticipate reverse current.

In the future grid, if the high reverse current from LV feeder to medium voltage feeder is not tackled properly residential DG owners would be forced to drive their units at low capacity. Current profile is shown in the Fig. 12. Reverse current reached $550 \mathrm{Amp}$ at $14 \mathrm{sec}$ but the fuse rating is 400 Amp. Though this is not a fault, the relay would pick up signal and trip the CB. The settings of the relays and rating of fuses need to be updated. 


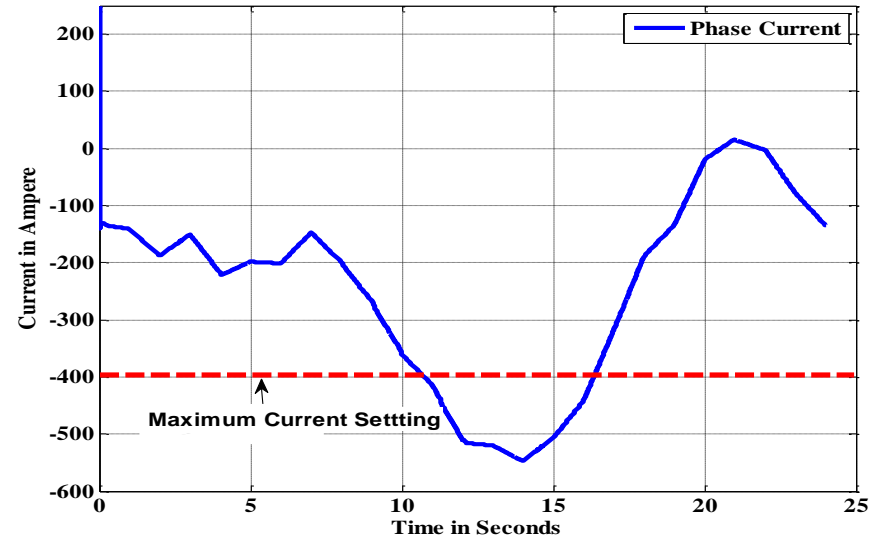

Fig. 12. Phase current profile at LV side of the transformer with DG

Three phase fault is applied between bus B11 and B12 at $14 \mathrm{sec}$ to evaluate the amount of current flowing through fuse as shown in Fig. 13. It is evident DGs at LV side that has caused reverse power flow would share a significant amount of fault current. During a fault, reverse current is less than threshold limits i.e. $400 \mathrm{Amp}$ and relay malfunctioning would be observed.

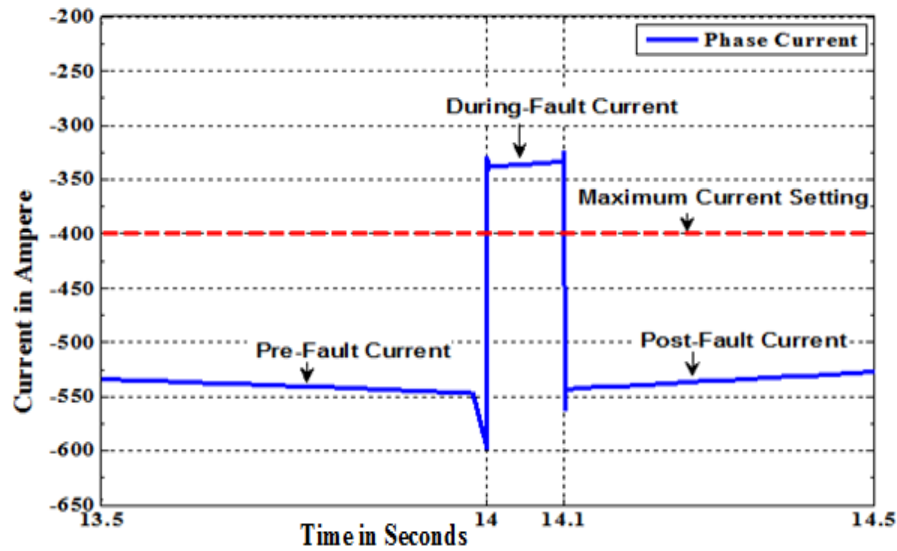

Fig. 13. Fault current contributed by the substation at $14 \mathrm{sec}$
C. Short circuit Analysis with $26 \%$ Wind, $53 \%$ PV, 39\% EVs and $40 \%$ Batteries

Fig. 14 shows the schematic diagram of UK active distribution network with DGs, EVs, batteries and domestic load. It is evident that placing ESB flow of power from the grid is towards home load and DGs are not causing reverse flow of power.

Fig. 15 shows phase current at LV network after adding energy storage batteries

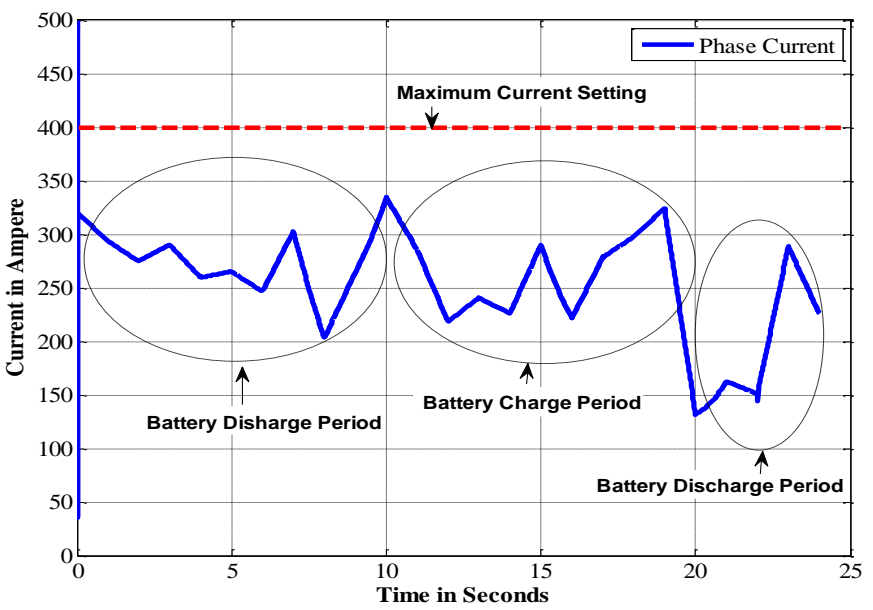

Fig. 15. Phase current profile at LV side of the transformer with DG, EV's and Batteries

Three phase fault is applied at 22 and removed at $22.1 \mathrm{sec}$ as shown in Fig. 16. Fault current is almost same as measured in Fig. 11 when there was no DG and uni-directional flow of power in a radial distribution feeder.

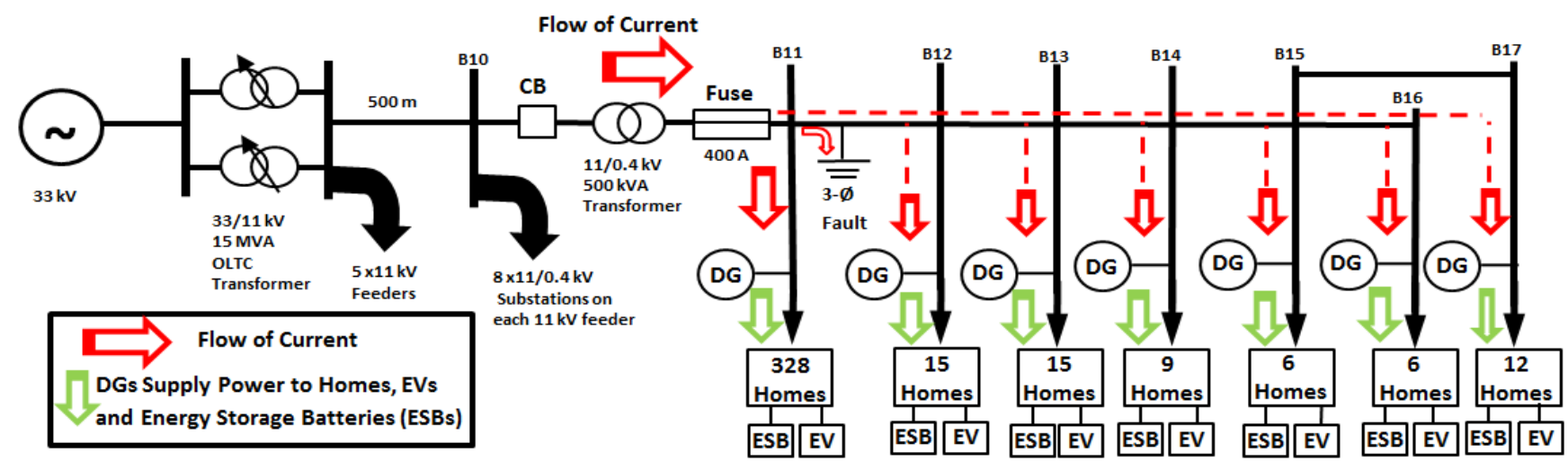

Fig. 14. Flow of current during fault with DGs, EVs and ESBs 


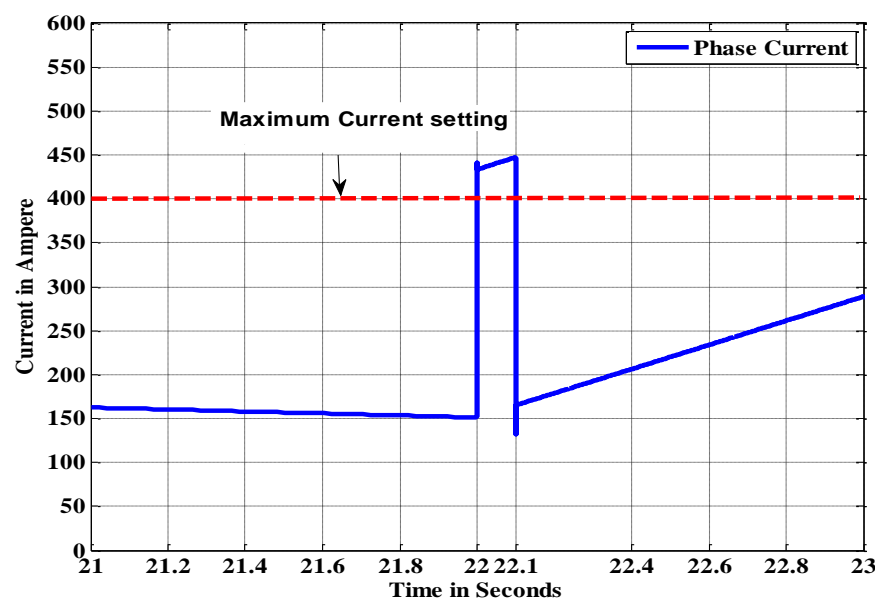

Fig. 16. Fault current contributed by the substation at $22 \mathrm{sec}$

Charging and discharging of ESB can be further managed to incorporate more DGs in a system based on fault current level. This fault level (450 amps) is almost the same as when no DG was connected to UK low voltage network.

\section{CONCLUSION}

The high penetration level of rooftop DGs at LV network would cause reverse flow of power from LV to MV network as home load consumption is less than DG power production. This result relay malfunctioning as a share of fault current from grid upon which relay pick up signal and trip CB is less than the threshold. Proper charging and discharging schedule of ESB causes the flow of power from the grid to LV network. Proper penetration modeling and selection of particular renewable DGs would create duration of time in which ESB can be charged and discharged properly. High penetration of wind power generation affects the time duration required for ESB to discharge as both ends of the day power production is more. The high penetration level of PVs is more suitable as compared with wind power generation because ESB would be able to charge during the daytime when PV production is maximum and discharge during both ends of the day when PV production is negligible. ESB in charge mode has caused extra load on LV distribution network so power and fault current again flow from MV to LV network. This scheme would also overcome the new settings required for relays during high DG penetration power production as feeder again behave as passive network though DGs are feeding LV network.

\section{REFERENCES}

[1] G. D. Carne, G. Buticchi, Z. Zou and M. Liserre, "Reverse power flow control in a ST-fed distribution grid", IEEE Transactions on Smart Grid, 2017 (Early Access), DOI 10.1109/TSG.2017.2651147.

[2] A. E. Naggar, I. Erlich, "Control approach of three-phase grid connected PV inverters for voltage unbalance mitigation in low-voltage distribution grids", IET Renewable Power Generation, vol. 10, pp. 1577 -1586 , Nov. 2016.

[3] T. L. Vandoorn, L. Degroote, et al, "Pilot project using curtailment to increase the renewable energy share on the distribution network", IET journals, 24th International Conference \& Exhibition on Electricity Distribution (CIRED), pp. 1370-1373, June 2017.

[4] D. Khani, A. Sadeghi and H. Madddi, "Impacts of Distributed Generation on Power System Transient and Voltage Stability", International Journal of Electrical Power and Energy Systems, Elsevier, vol. 43, pp. 488-500, Dec. 2012.

[5] Y. A. I. Mohamed, "New Control Algorithms for the Distributed Generation Interface in Grid-Connected and Micro-grid Systems", Ph.D. dissertation, University of Waterloo, Ontario, Canada, 2008.

[6] J. Desus, S. Grenard, et al, "Effective Impact of DER on Distribution System Protection", 19th International conference on electricity distribution, Vienna, 21-24 May 2007.

[7] A. F. Sarabia, "Impact of Distributed Generation on Distribution System", MSc thesis, Aalborg University, Denmark, June 2011.

[8] K Kauhaniemi, L. Kumpulainen, P. Buchanan, "Impact of Distributed Generation on the Protection of Distribution Networks", University of Vaasa, Finland, VTT Technical Research Centre of Finland, Finland, Manitoba HVDC Research Centre, Electric Energy online, 2004.

[9] P. Suwanapingkarl, "Power quality analysis of future power network", Ph.D. thesis, University of Northumbria, Newcastle, UK, November 2012.

[10] S. Ali, N. Pearsall, G. Putrus, "Using Electric Vehicles To Mitigate Imbalance Requirements Associated With High Penetration Level Of Grid-Connected Photovoltaic Systems", 22nd International Conference on Electricity Distribution, Stockholm, 10-13 June 2013.

[11] Koyanagi, T. Inuzuka, Y. Uriu, R. Yokoyama, "Monte Carlo simulation on the demand impact by quick chargers for electric vehicles", IEEE Power Engineering Society, Edmonton, Alta., Canada, pp. 1031-1036, 18-22 July 1999.

[12] Mott MacDonald, "System integration of additional micro generation", (SIAM) (DG/CG/00028/REP). UK: Department of trade and industry (DTI) \& OFGEM, 2004.

[13] Department for Transport (DFT) National travel survey: 2010 Trips in progress by time of day of week - index: Great Britain, UK, 2011.

[14] Paul, Erik, Brendan and Michael, "The role of energy storage with renewable electricity generation", National Renewable Energy Laboratory, NREL/TP-6A2-47187, Jan 2010.

[15] Tony Haggis, "Network Design Manual", e.on, central networks, Dec. 2006. 